\title{
Profil Penurunan Tekanan Darah (hipotensi) pada Pasien Sectio Caesarea yang Diberikan Anestesi Spinal dengan Menggunakan Bupivakain
}

\author{
${ }^{1}$ Popi Tanambel \\ ${ }^{2}$ Lucky Kumaat \\ ${ }^{2}$ Diana Lalenoh
}

\author{
${ }^{1}$ Kandidat Skripsi Fakultas Kedokteran Universitas Sam Ratulangi Manado \\ ${ }^{2}$ BagianAnestesiologi danTerapi Intensif RSUP Prof. Dr. R. D. Kandou Manado \\ Email: popitanambel12082@gmail.com
}

\begin{abstract}
Cesarean section is generally performed on pregnant women and the prevalence is continuously increasing every years. This study was aimed to determine the profile of the occurence of hypotension in patients of sectio caesarea with spinal anesthesia using bupivacaine at Prof. Dr. R. D. Kandou Manado. This was a descriptive retrospective study. Data were obtained from the emergency operation room at Prof. Dr. R. D. Kandou Manado from November through December 2015. The results showed that there were 15 cases of cesarean section with spinal anesthesia using bupivacaine. According to age group, there was 1 patient $(6.66 \%)$ in age group <20 years; 11 patients $(73.33 \%)$ in age group 20-35 years; and 3 patients $(20 \%)$ in age group $>35$ years. After spinal anaesthesia using bupivacaine, the highest percentage of decrease in systolic blood pressure was $18.18 \%$, meanwhile of diastolic blood pressure was $11.11 \%$. Conclusion: The decreases in systolic blood pressure and diastolic blood pressure after spinal anesthesia using bupivacaine were within normal limits.
\end{abstract}

Keywords: spinal anesthetic, bupivacaine, hypotension

\begin{abstract}
Abstrak: Sectio caesarea (SC) merupakan operasi yang umum dan luas dilakukan pada wanita hamil dan prevalensi meningkat setiap tahun. Penelitian ini bertujuan untuk mengetahui profil kejadian hipotensi pada pasien SC yang diberikan anestesi spinal dengan bupivakain di RSUP Prof. Dr. R. D. Kandou Manado. Jenis penelitian ialah deskriptif retrospektif. Data penelitian diambil dari ruang operasi darurat periode November 2015 sampai Desember 2015. Hasil penelitian mendapatkan 15 kasus bedah SC dengan menggunakan teknik anestesi spinal. Berdasarkan golongan usia, ditemukan kelompok usia $<20$ tahun sebanyak 1 pasien $(6,66 \%)$; usia 20-35 tahun sebanyak 11 pasien $(73,33 \%)$; dan usia $>35$ tahun sebanyak 3 pasien $(20 \%)$. Persentase penurunan tekan darah sistolik yang paling tinggi sesudah dilakukan anestesi spinal ialah sebesar 18,18\% sedangkan untuk tekanan darah diastolik paling tinggi mencapai $11,11 \%$. Simpulan: Penurunan tekan darah sistolik dan tekanan darah diastolik sesudah dilakukan anestesi spinal masih berada dalam batas normal.

Kata kunci: anestesi spinal, bupivakain, hipotensi
\end{abstract}

Sectio caesarea (SC) merupakan operasi yang umum dan luas dilakukan pada wanita hamil dan prevalensi meningkat setiap tahun. ${ }^{1}$ Di Indonesia angka persalinan dengan SC di 12 Rumah Sakit Pendidikan berkisar 2,1-11,8\%; di RS Sanglah Denpasar insiden SC selama sepuluh tahun
(1984-1994) 8,06\%-20,23\%, dengan rerata pertahun $13,6 \%$, sedangkan tahun 19941996 angka kejadian SC 17,99\% dan angka kejadian persalinan bekas SC $18,40 \% .^{2}$

Obstetric Anesthesia Guidelines merekomendasikan teknik anestesi spinal ataupun epidural dibandingkan dengan 
anestesi umum untuk sebagian besar SC. Di Amerika Serikat pada tahun 1992, anestesi spinal digunakan lebih dari $80 \%$ pada SC. ${ }^{3}$ Anestesi spinal memberikan beberapa keuntungan, antara lain adalah ibu akan tetap terbangun yang dapat mengurangi kemungkinan terjadi aspirasi dan menghindari depresi neonatus. ${ }^{4}$ Salah satu komplikasi yang sering terjadi pada anestesi spinal ialah hipotensi. ${ }^{5}$ Anestesi spinal dapat mengakibatkan penurunan tajam pada tekanan darah ibu yang akan memengaruhi keadaan ibu dan bayi. ${ }^{6}$

Terjadinya hipotensi berkaitan dengan tingginya blokade spinal. Semakin tinggi blokade spinal, mekanisme kompensasi akibat hambatan simpatis pun akan semakin ditekan. ${ }^{7,8}$ Hipotensi pada anestesi spinal terutama akibat dari blokade saraf simpatis yang befungsi mengatur tonus otot polos pembuluh darah. Blokade serabut saraf simpatis preganglionik yang menyebabkan vasodilatasi vena, sehingga terjadi pergeseran volume darah terutama ke bagian splanik dan juga ekstremitas bawah sehingga akan menurunkan aliran darah balik ke jantung. ${ }^{9}$

Angka kejadian hipotensi pada SC dilaporkan sebanyak 50\%-60\%. ${ }^{10}$ Chung et al. ${ }^{11}$ dengan $12 \mathrm{mg}$ bupivakain hiperbarik $0,5 \%$, mendapatkan insidens hipotensi $80 \%$. Penelitian Riley et al. ${ }^{12}$ dan SiddikSayyid et al. ${ }^{13}$ dengan $12 \mathrm{mg}$ bupivakain hiperbarik $0,75 \%$ mendapatkan insidens hipotensi sebesar $85 \%$ dan $87 \%$. Selaras dengan Chung et al. ${ }^{11}$, Bryson et al. ${ }^{14}$, mendapatkan insidens hipotensi yang lebih dari $70 \%$, sedangkan Bogra et al. ${ }^{15}$, Suwardi ${ }^{16}$, dan Akmal $^{17}$ dengan 12,5 mg bupivakain hiperbarik $0,5 \%$ mendapatkan insidens hipotensi sebesar 50\%, 46\%, 42\%. Penggunaan anestetik lokal dengan dosis yang lebih kecil tidak memblok serabut saraf simpatis di daerah atas sehingga hipotensi tidak terjadi. Penggunaan dosis kecil akan memperkecil risiko timbulnya toksisitas sistemik obat anestetik lokal. ${ }^{18,19}$

Pernelitian ini bertujuan untuk mendapatkan profil penurunan tekanan darah (hipotensi) pada pasien SC yang diberi anestesi spinal dengan bupivakain.

\section{METODE PENELITIAN}

Jenis penelitian ini ialah deskriptif prospektif. Penelitian ini dilaksanakan di RSUP Prof. Dr. R. D. Kandou periode November-Desember 2015. Populasi target dari penelitian ini ialah seluruh pasien yang menjalani SC di RSUP Prof. Dr. R. D. Kandou. Sampel penelitian ini ialah seluruh pasien yang menjalani pembedahan SC dengan menggunakan anestesi spinal di RSUP Prof. Dr. R. D. Kandou yang memenuhi kriteria inklusi.

\section{HASIL PENELITIAN}

Penelitian ini dilaksanakan pada bulan November 2015 sampai Desember 2015 di RSUP Prof. Dr. R. D. Kandou Manado dan mendapatkan 15 kasus SC dengan menggunakan anestesi spinal.

Tabel 1 menunjukkan bahwa dari 15 kasus bedah SC dengan menggunakan teknik anestesi spinal yang digolongkan menurut usia, ditemukan kelompok usia di bawah <20 tahun sebanyak 1 pasien (6,66\%); usia 20-35 tahun sebanyak 11 pasien $(73,33 \%)$, sedangkan untuk usia $>35$ tahun sebanyak 3 pasien (20\%).

Tabel 1. Distribusi pasien bedah sesar dengan anestesi spinal menurut usia

\begin{tabular}{ccc}
\hline $\begin{array}{c}\text { Golongan usia } \\
\text { (tahun) }\end{array}$ & $\begin{array}{c}\text { Jumlah } \\
\text { pasien }\end{array}$ & \% \\
\hline$<20$ & 1 & 6,66 \\
$20-35$ & 11 & 73,33 \\
$>35$ & 3 & 20 \\
Jumlah & 15 & 100 \\
\hline
\end{tabular}

Tabel 2 menunjukkan bahwa pasien SC yang masuk kategori ASA I berjumlah 0 sedangkan yang masuk kategori ASA II berjumlah 15 pasien atau sebesar 100\%.

Tabel 2. Distribusi pasien menurut ASA

\begin{tabular}{ccc}
\hline $\begin{array}{c}\text { Kategori } \\
\text { ASA }\end{array}$ & $\begin{array}{c}\text { Jumlah } \\
\text { Pasien }\end{array}$ & $\%$ \\
\hline I & 0 & 0 \\
II & 15 & 100 \\
\hline
\end{tabular}

Tabel 3 menunjukkan bahwa tekanan darah sistolik (TDS) awal $110 \mathrm{mmHg}$ berjumlah 2 pasien $(13,33 \%)$; TDS awal 
$120 \mathrm{mmHg}$ berjumlah 6 pasien (40\%); TDS awal $130 \mathrm{mmHg}$ berjumlah 2 pasien $(13,33 \%)$; sedangkan untuk TDS awal 140 mmHg berjumlah 5 pasien $(33,33 \%)$.

Tabel 3. Distribusi pasien menurut tekanan darah sistolik awal (TDS) sebelum anestesi spinal

\begin{tabular}{ccc}
\hline $\begin{array}{c}\text { TDS awal } \\
(\mathbf{m m H g})\end{array}$ & Jumlah pasien & \% \\
\hline 110 & 2 & 13,33 \\
120 & 6 & 40 \\
130 & 2 & 13,33 \\
140 & 5 & 33,33 \\
Jumlah & 15 & 100 \\
\hline
\end{tabular}

Tabel 4 menunjukkan bahwa sebelum anestesi spinal didapatkan TDD awal 70 mmHg berjumlah 4 pasien $(26,66 \%)$; TDD awal $80 \mathrm{mmHg}$ berjumlah 1 pasien (6,66\%); TDD $90 \mathrm{mmHg}$ berjumlah 5 pasien (33,33\%); dan TDD awal 100 mmHg berjumlah 5 pasien $(33,33 \%)$.

Tabel 4. Distribusi pasien menurut tekanan darah diastolik awal (TDD) sebelum anestesi spinal

\begin{tabular}{ccc}
\hline $\begin{array}{c}\text { TDD awal } \\
(\mathbf{m m H g})\end{array}$ & Jumlah pasien & $\boldsymbol{\%}$ \\
\hline 70 & 4 & 26,66 \\
80 & 1 & 6,66 \\
90 & 5 & 33,33 \\
100 & 5 & 33,33 \\
Jumlah & 15 & 100 \\
\hline
\end{tabular}

Tabel 5 menunjukkan persentase penurunan TDS sesudah anestesi spinal bervaiasi, yaitu: penurunan sebesar $4,54 \%$ (1 pasien); 8,33\% (5 pasien); 5,71\% (1 pasien); $18,18 \%$ (1 pasien); $13,84 \%$ (1 pasien); $0,89 \%$ (1 pasien); 3,57\% (2 pasien); 14,28\% (1 pasien); 7,69\% (1 pasien); dan $10,71 \%$ (1 pasien).

Tabel 6 menunjukkan bahwa tidak terjadi penurunan TDD sesudah anestesi spinal pada 3 pasien. Persentase penurunan TDD sesudah anestesi spinal bervariasi, yaitu: sebesar 5\% (1 pasien); 7,14\% (1 pasien); $10 \%$ (4 pasien); dan 11,11\% (6 pasien).
Tabel 5. Distribusi pasien menurut penurunan TDS sesudah anestesi spinal

\begin{tabular}{cccc}
\hline $\begin{array}{c}\text { TDS } \\
\text { sebelum } \\
\text { anestesi }\end{array}$ & $\begin{array}{c}\text { TDS } \\
\text { sesudah } \\
\text { anestesi }\end{array}$ & Penurunan & $\%$ \\
\hline 110 & 105 & 5 & 4,54 \\
120 & 110 & 10 & 8,33 \\
140 & 132 & 8 & 5,71 \\
110 & 90 & 20 & 18,18 \\
130 & 112 & 18 & 13,84 \\
120 & 110 & 10 & 8,33 \\
120 & 119 & 1 & 0,83 \\
140 & 135 & 5 & 3,57 \\
140 & 120 & 20 & 14,28 \\
130 & 120 & 10 & 7,69 \\
120 & 110 & 10 & 8,33 \\
120 & 110 & 10 & 8,33 \\
140 & 135 & 5 & 3,57 \\
140 & 125 & 15 & 10,71 \\
120 & 110 & 10 & 8,33 \\
\hline
\end{tabular}

Tabel 6. Distribusi pasien menurut penurunan TDD sesudah anestesi spinal

\begin{tabular}{cccc}
\hline $\begin{array}{c}\text { TDD } \\
\text { sebelum } \\
\text { anestesi }\end{array}$ & $\begin{array}{c}\text { TDD } \\
\text { sesudah } \\
\text { anestesi }\end{array}$ & Penurunan & $\%$ \\
\hline 70 & 70 & 0 & 0 \\
70 & 70 & 0 & 0 \\
100 & 90 & 10 & 10 \\
70 & 65 & 5 & 7,14 \\
100 & 90 & 10 & 10 \\
90 & 80 & 10 & 11,11 \\
70 & 70 & 0 & 0 \\
100 & 90 & 10 & 10 \\
100 & 95 & 5 & 5 \\
90 & 80 & 10 & 11,11 \\
90 & 80 & 10 & 11,11 \\
90 & 80 & 10 & 11,11 \\
100 & 90 & 10 & 10 \\
90 & 80 & 10 & 11,11 \\
90 & 80 & 10 & 11,11 \\
\hline
\end{tabular}

Tabel 7 menunjukkan bahwa persentase penurunan dari MAP awal ke MAP sesudah anestesi spinal bervariasi, yaitu: penurunan sebesar $2 \%$ (1 pasien); 3,85\% (1 pasien); 8,24\% (1 pasien); $12 \%$ (1 pasien); 11,52\% (1 pasien); 10\% (4 pasien); 0,38\% (1 pasien); 7,35\% (2 pasien); $8,82 \%$ (1 pasien); 9,68\% (1 
Tanambel, Kumaat, Lalenoh: Profil penurunan tekanan darah (hipotensi) ...

pasien); dan $10,94 \%$ (1 pasien).

Tabel 7. Distribusi pasien menurut Mean Arterial Pressure (MAP) sebelum dan sesudah anestesi spinal

\begin{tabular}{ccc}
\hline $\begin{array}{c}\text { MAP } \\
\text { Awal }\end{array}$ & $\begin{array}{c}\text { MAP } \\
\text { Sesudah } \\
\text { Anestesi }\end{array}$ & $\begin{array}{c}\text { Persentase } \\
(\%)\end{array}$ \\
\hline 83,33 & 81,67 & 2 \\
86,67 & 83,33 & 3,85 \\
113,33 & 104 & 8,24 \\
83,33 & 73,33 & 12 \\
110 & 97,33 & 11,52 \\
100 & 90 & 10 \\
86,67 & 86,33 & 0,38 \\
113,33 & 105 & 7,35 \\
113,33 & 103,33 & 8,82 \\
103,33 & 93,33 & 9,68 \\
100 & 90 & 10 \\
100 & 90 & 10 \\
113,33 & 105 & 7,35 \\
106,67 & 95 & 10,94 \\
100 & 90 & 10 \\
\hline
\end{tabular}

\section{BAHASAN}

Berdasarkan penelitian yang telah dilakukan di ruang operasi darurat $(\mathrm{OK}$ cito) RSUP Prof. Dr. R. D. Kandou Manado pada periode November 2015 sampai Desember 2015, diperoleh 15 kasus operasi SC yang menggunakan anestesi spinal dengan obat anestetik lokal bupivakain.

Jumlah kasus yang paling banyak ditemukan berada pada kelompok usia 2035 tahun (73,33\%) (Tabel 1). Distribusi pasien menurut kategori ASA (Tabel 2) menunjukan bahwa pasien SC yang masuk kategori ASA II berjumlah 15 pasien (100\%), dan tidak ada yang masuk kategori ASA I (0\%).

Distribusi pasien menurut TDS awal sebelum anestesi spinal menunjukk an bahwa TDS seluruh pasien sangat bervariasi yaitu secara berurut: TDS awal $120 \mathrm{mmHg}$ berjumlah 6 pasien (40\%); TDS awal $140 \mathrm{mmHg}$ berjumlah 5 pasien (33,33\%); dan TDS awal $130 \mathrm{mmHg}$ berjumlah 2 pasien $(13,33 \%)$.
Berdasarkan data distribusi pasien menurut TDS sesudah anestesi spinal, menunjukkan bahwa terjadi penurunan TDS untuk seluruh pasien. Persentase penurunan TDS yang paling tinggi mencapai $18,18 \%$. Persentase penurunan TDD yang paling tinggi mencapai $11,11 \%$. Terdapat 3 pasien yang tidak mengalami penurunan TDD sesudah anestesi spinal.

Penurunan tekanan darah yang terjadi disebabkan oleh beberapa faktor, antara lain tinggi pasien, $r$ usia, dan obat yang digunakan. Hal ini sesuai dengan pernyataan Winarno dan Sutiyono ${ }^{20}$ yang menyatakan bahwa teknik anestesi spinal ditentukan oleh banyak faktor, salah satu diantaranya ialah dosis obat. Penggunaan dosis bupivakain sebagai anestesik lokal dalam anestesi spinal yang disarankan pada beberapa literatur ialah 12-15 mg dengan mula kerja 5- 10 menit, lama kerja antara 90-120 menit. Sejumlah penelitian berusaha menentukan dosis bupivakain, tetapi hasil temuan yang ada berbeda-beda dengan dosis berkisar 5-20 $\mathrm{mg}$. Penggunaan dosis rendah bertujuan untuk mengurangi risiko terjadinya hipotensi. ${ }^{20}$

Dari hasil suatu penelitian dikatakan bahwa berat dan tinggi badan merupakan variabel yang signifikan untuk memrediksi ketinggian maksimal blokade anestesi spinal. Tinggi badan dan berat badan memberikan pengaruh terhadap penyebaran blokade anestesi yang luas sehingga dosis bupivakain yang digunakan harus disesuaikan. Penelitian yang dilakukan pada tahun 2004 menyatakan bahwa dosis bupivakain hiperbarik yang disesuaikan dengan tinggi badan dan berat badan pasien jika digunakan kombinasi dengan diamorfin 0,4 $\mathrm{mg}$ akan memberikan level anestesia yang optimal pada pasien yang menjalani seksio sesarea. ${ }^{21}$ Hasil penelitian lain juga memperlihatkan bahwa penyuntikan lambat bupivakain hiperbarik $10 \mathrm{mg}$ selama 60 detik dan 120 detik dapat mengurangi insidensi serta efek samping hipotensi selama anestesi spinal pada operasi seksio sesarea. ${ }^{22}$ 


\section{SIMPULAN}

Dari hasil penelitian yang dilakukan terhadap pasien yang menjalani operasi sectio caesarea dengan anestesi spinal menggunakan bupivakain di ruang operasi darurat RSUP Prof. Dr. R. D. Kandou Manado periode November-Desember 2015, dapat disimpulkan bahwa penurunan tekan darah sistolik dan tekanan darah diastolik sesudah dilakukan anestesi spinal masih berada dalam batas normal.

\section{DAFTAR PUSTAKA}

1. Gondo HK, Sugiharta K. Profil operasi seksio sesarea di SMF obstetri \& ginekologi RSUP Sanglah Denpasar, Bali tahun 2001 dan 2006. CKD. 2010;37:97-101.

2. Afolabi BB, Lesi FEA, Merah NA. Regional versus general anesthesia for cesarean section (Review). The Cochrane Collaboration. 2006;4:1-44.

3. Petropoulos G, Siristatidis C, Salamalekis E, Creatsas G. Spinal and epidural versus general anesthesia for elective cesarean section at term: effect on the acid base status of the mother and newborn. J Mat-Fet \& Neon Med. 2003;13:260-6.

4. Brown DL. Local anesthesia toxicity. In: Finucane BT. Complication of Regional Anesthesia. NewYork: Churchill Livingstone, 2000.

5. Birnbach DJ. General anesthesia for cesarean section-who needs it? European Society of Anaesthesiologists, Refresher Course. 2003:165-7.

6. Wlody D. Complication of regional anesthesia in obstetrics. Clin Obstet Gynecol. 2003;46:667-78.

7. Ronald D, Miller MD. Anesthesia (6th ed). New York: Churchill Livingstone, 2005; p. 232-329.

8. Flora L, Redjeki SI, Wargahadibrata HA. Perbandingan efek anestesi spinal dengan anestesi umum terhdap kejadian hipotensi dan nilai APGAR bayi pada seksio sesarea. Jurnal Anestesi Perioperatif. 2014;2:105-6.

9. Sahoo T, Sendasgupta C, Goswami A, Hazra A. Reduction in spinal-induced hypotension with ondansetron in parturients undergoing caesarean section: a double-blind randomised, plasebocontrolled study. Int $\mathbf{J}$ Obstet Anesthesia. 2012;2(1):24-8.

10. Chung CJ, Choi SR, Yeo KH, Park HS, Lee SI, Chin YJ. Hyperbaric spinal ropivacaine for cesarean delivery: A comparison to hyperbaric bupivacaine. Anesth Analg. 2001;93:157-61.

11. Riley E, Cohen SE, Rubenstein AJ, Flanagan B. Prevention of hypertension after spinal anesthesia for cesarean section: $6 \%$ hetastarch versus lactated Ringer's solution. Anesth Analg. 1995;81:838-42.

12.Siddik-Sayyid SM, Aouad MT, Jalbout MI, Zalaket MI, Berzina CE, Baraka AS. Intrathecal versus intravenousfentanyl for supplementation of subarachnoid block during cesarean delivery. Anesth Analg. 2002;95:209

13. Bryson GL, Macneil R, Jeyaraj LM, Rosaeg OP. Small dose spinal bupivacaine for caesarean delivery does not reduce hypotension but accelerates motor recovery. Can J Anesth. 2007;54:531-7.

14. Bogra J, Arora N, Srivastava P. Synergis effect of intrathecal fentanyl and bupivacaine in spinal anesthesia forcesarean section. BMC Anesthesiol. 2005;5:5.

15. Suwardi C. Perbandingan analgesia spinal pada bedah sesar antara kombinasi 10 mg bupivakain hiperbarik 0,5\% + 12,5 mcg dengan 12,5 mg bupivakain hiperbarik 0,5\%. Jakarta: FKUI; 2005.

16. Akmal E. Penyebaran anestetik lokal dan efek hemodinamik pada operasi seksio sesaria dalam anestesia spinal. Jakarta: FKUI; 2008.

17. Russel F, Holmqvist ELO. Subarachnoid analgesia for caesarean section. Br J Anaesth. 1987;59:347-53.

18. Richardson MG, Collins HV, Wissler R. Intrathecal plain vs hyperbaric bupivacaine with mophine for cesarean section: A comparison of effectiveness, side-effects and sedation. Anesthesiol. 1997;87:A890.

19. Barbeau TR. Cardiovascular physiology. Florence: Francis Marion University, 2004.

20. Winarno I, Sutiyono D. Jarum spinal dan pengaruh yang mungkin terjadi. Jurnal Anestesiologi Indonesia. 2009;1(3):

21. Rodrigues FR, Brandao MJN. Regional 
Tanambel, Kumaat, Lalenoh: Profil penurunan tekanan darah (hipotensi) ...

anesthesia for cesarean section in obese pregnant woman: a retrospective study.

Rev Bras Anestesiol. 2011;61(1):13-20.

22.Singh SI, Morley-Forster PK, Shamsah M.
Influence of injection rate of hyperbaric bupivacaine on spinal block in parturients: a randomized trial. Can J Anesth.2007;54(4):290-5. 